MATEC Web of Conferences 6, 03003 (2013)

DOI: $10.1051 /$ matecconf $/ 20130603003$

(C) Owned by the authors, published by EDP Sciences, 2013

\title{
Fire spalling in concrete - The moisture effect, part II
}

\author{
R. Jansson and L. Boström \\ SP Technical Research Institute of Sweden
}

\begin{abstract}
A compressive strength reduction effect of almost $40 \%$ has been shown for small mortar specimens with a moisture content of $8 \%$ boiled in water for 3,10 or 20 minutes compared with dried specimens. This shows that the presence of moisture can be a plausible factor that reduces the strength in areas where spalling in the form of surface flaking during fire exposure occurs.
\end{abstract}

\section{INTRODUCTION}

During fire testing it is common that cold water can be observed pouring out of the cold side of concrete elements that are exposed to one side fire exposure. At the beginning of the test saturated areas rarely exist in the cross-section, but after a certain amount of time condensation of vapour transported from the hot side builds up a saturated layer that is moved by the pressure gradient. In theory the geometry of these saturated areas could be evenly distributed as assumed when showing 1-D representations of this phenomenon, see Figure 1, but in practice a more complex moisture transfer along cracks, newly created or present from the start of heating, is likely. The second case is probably the reason for moisture pouring out of the non-exposed side of slabs as this does not necessarily indicate that the whole slab is fully saturated. The reason for this is that there is not enough moisture driven off from the hot surface layers to saturate the whole specimen, so pathways for moisture transfer (cracks) must be present or created to move liquid moisture to the cold side. If no cracks exist it is also physically impossible to push water through, e.g. a $150 \mathrm{~mm}$ solid concrete in 30 minutes which has been observed during fire testing.

Regarding stresses that can lead to cracks, this can be illustrated by curvature measurements during fire exposure of slabs. In the case of fire exposure of slabs, directly after the start of fire exposure the whole specimens usually starts to bend which indicates that the stresses in the hot zone are not only influencing that zone, but also the cold parts of the cross-section. An example of the curvature created in a fire exposed slab can be seen in Figure 2.

During standard fire exposure, ISO 834, the temperature in the zone that the flaking is happening in is often well beyond temperatures where the saturation vapour pressure is significant, see figure 3 . At $200^{\circ} \mathrm{C}$ the saturation vapour pressure is approximately $1.5 \mathrm{MPa}$. It has also been seen from pressure measurements inside concrete that spalls during standard fire exposure that the recorded pressure never reached values approaching the tensile strength of the material before spalling takes place [4]. This indicates that the steam pressure is not the dominating factor governing the spalling process during standard fire exposure. Instead the influence of the presence of moisture in this critical zone might explain the behaviour. In Fire spalling in concrete - The moisture effect, part I (presented at the first fire spalling workshop), the development of saturated areas inside concrete after 15 minutes of standard fire exposure was shown experimentally by splitting concrete specimens [5]. By using this technique, saturated zones under $100^{\circ} \mathrm{C}$ could be monitored. Over $100{ }^{\circ} \mathrm{C}$ the moisture is instantaneously evaporated during splitting making it impossible to see but in theory saturation could be

This is an Open Access article distributed under the terms of the Creative Commons Attribution License 2.0, which permits unrestricted use, distribution, and reproduction in any medium, provided the original work is properly cited. 


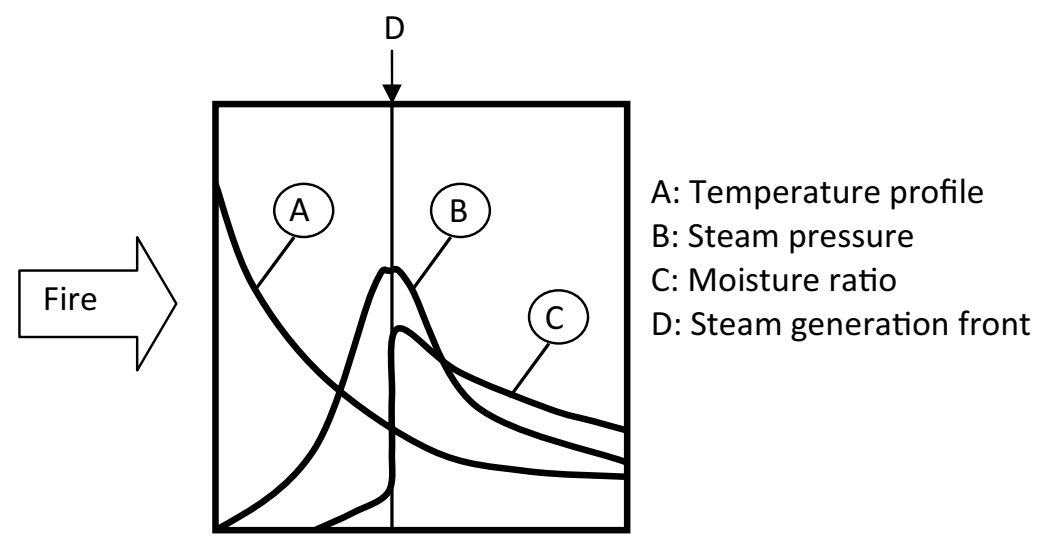

Figure 1. Schematic figure of fire exposed concrete (redrawn from ref [1] but similar to principal drawing in ref [2]).

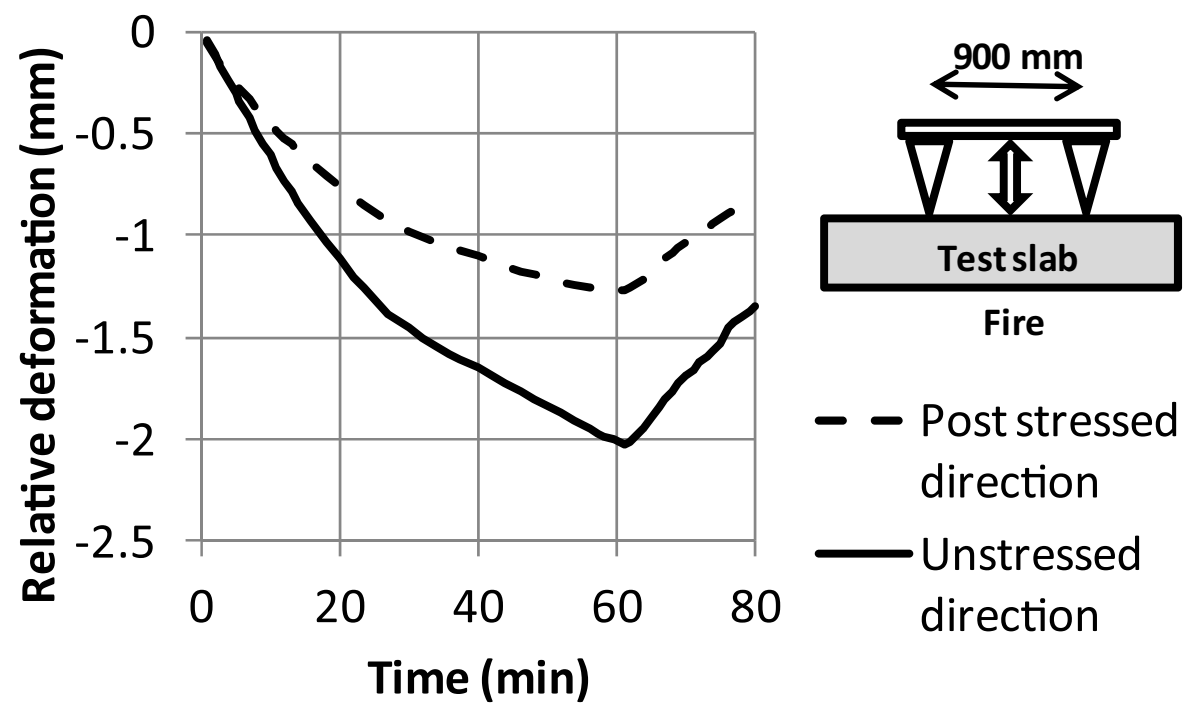

Figure 2. Curvature, relative deformation of the measurement length $900 \mathrm{~mm}$, created in a $1700 \times 1200 \times$ $200 \mathrm{~mm}^{3}$ reinforced slab post stressed in the $1700 \mathrm{~mm}$ direction [3].

present well above $100{ }^{\circ} \mathrm{C}$ in pressurized small pores. It is therefore interesting to further examine the influence on the mechanical properties of the presence of water at elevated temperatures and if possible to try to separate the influence of moisture pressure on this reduction.

Bazant and Prat made a study of the influence on fracture energy of temperature and humidity by making tests on dried samples and tests on wet samples under water [6]. In this study it was found that the fracture energy difference between wet and dry samples was low at room temperature but significant at 62 and $90^{\circ} \mathrm{C}$ as shown in Figure 4. This result shows the importance of considering the effect of the presence of water at elevated temperatures.

According to Lankard et al. [7] moisture contained inside concrete during heating leads to a dramatic reduction of the compressive strength, see Figure 5. The measurements were performed inside an autoclave to reduce the moisture loss by having the saturation vapour pressure around the specimen during heating. 


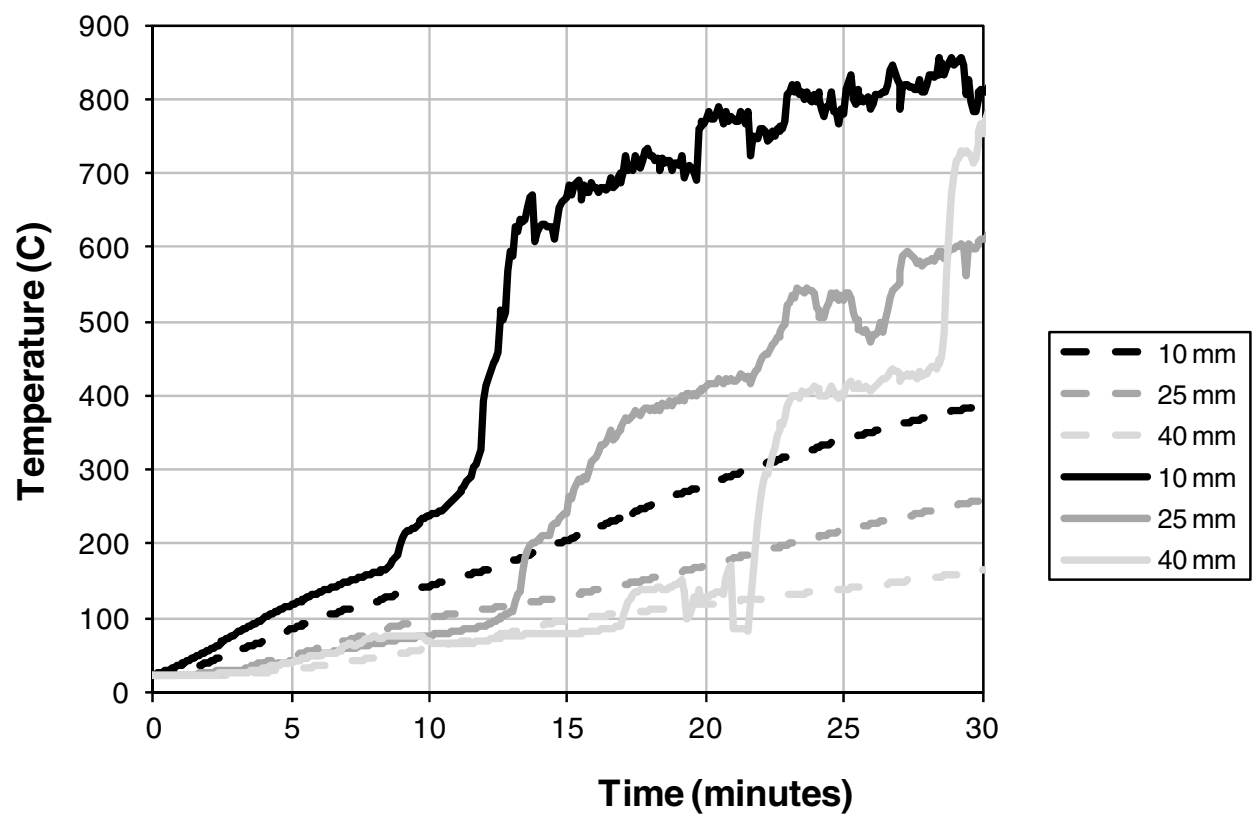

Figure 3. Temperature measurement showing that temperature development in a fire test with standard fire exposure of post stressed $1700 \times 1200 \times 200 \mathrm{~mm}^{3}$ slabs. Continuous lines from a specimen that spalled and dashed line from a specimen that did not spall.

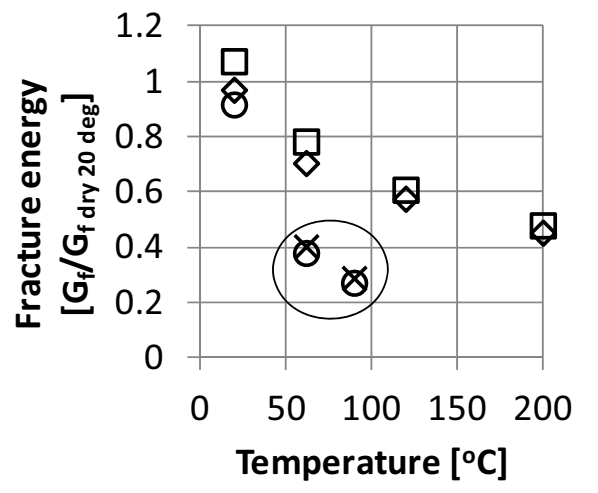

$$
\begin{aligned}
& \diamond \text { 3-point } \\
& \text { bending, dry } \\
& 28 \mathrm{~d} \\
& \square \text { Eccentric } \\
& \text { compression, } \\
& \text { dry 28d } \\
& 03 \text {-point } \\
& \text { bending, wet } \\
& 28 \mathrm{~d} \\
& \times 3 \text {-point } \\
& \text { bending, wet } \\
& 41 \mathrm{~d}
\end{aligned}
$$

Figure 4. Influence from moisture and temperature on fracture energy [6].

\section{MATERIALS AND TEST METHOD}

The influence of moisture and temperature on the strength of mortar has been investigated. Despite the fact that the fire spalling of concrete is the main focus in the present study the test series performed has been made on mortar, a mix of cement, sand and water without larger aggregates. By using small specimens, $20 \times 20 \times 40 \mathrm{~mm}^{3}$, the time to reach thermal equilibrium in the specimen is short and local differences in strength at the surface or in the centre in larger standard cores boiled for very long time to reach thermal equilibrium is minimised. Also the time scale for the experiment is closer to when real spalling evens starts during standard fire exposure (5-20 minutes). 


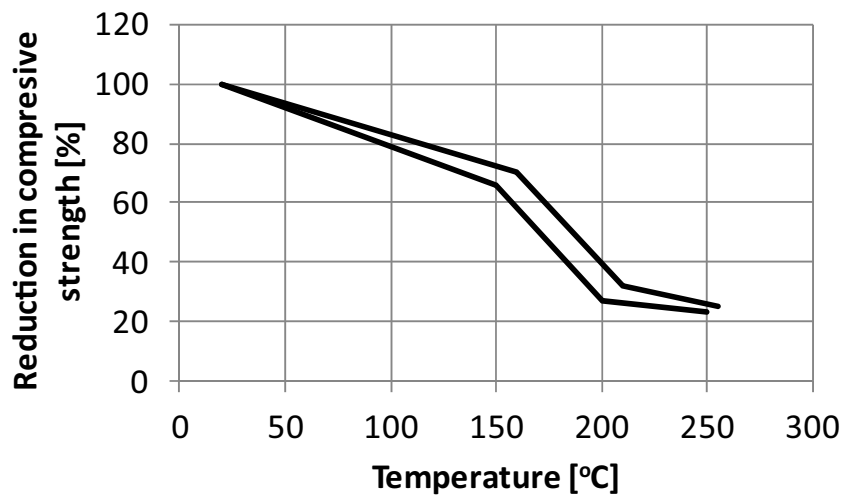

Figure 5. Influence of temperature on compressive strength if moisture is kept inside the specimen by using an autoclave with the saturation pressure for steam as the boundary [7].

Table 1. Mortar mixes specified for one batch of three test specimens according to EN-196-1:2005 [8].

\begin{tabular}{|l|l|l|l|}
\hline Name & OPP & 2PP* & 4PP* \\
\hline Water [g] & 225 & 225 & 225 \\
\hline Cement [g], CEM II/A-LL 42,5 R & 450 & 450 & 450 \\
\hline w/c & 0.5 & 0.5 & 0.5 \\
\hline CEN Reference sand [g] & 1350 & 1350 & 1350 \\
\hline PP fibres [g] & 0 & $2.25^{* *}$ & $4.5^{* *}$ \\
\hline $\begin{array}{l}\text { Equivalent PP-fibre addition in a Swedish } \\
\text { tunnel concrete*** with the same amount } \\
\text { of fibres per cement paste }\left[\mathrm{kg} / \mathrm{m}^{3}\right]\end{array}$ & 0 & 2 & 4 \\
\hline
\end{tabular}

* Note that the name of the mix is based on the amount of polypropylene (PP) fibres added in a real concrete to get the same amount of fibres per $\mathrm{m}^{3}$ as in the mortar mix tested.

**Not specified in EN-196-1:2005 [8].

$* * * v / c=0.4$ and $426 \mathrm{~kg} / \mathrm{m}^{3}$ cement.

The test material used and the mixing procedure followed the definition in EN 196-1:2005 [8] where standardized sand is mixed with cement and water to a water/cement ratio of 0.5 , see Table 1 . The mortar is then moulded in prism moulds, $40 \times 40 \times 160 \mathrm{~mm}^{3}$, which are jolted in a standardized jolting apparatus. After form stripping the specimens were placed under water for half a year before cutting into $20 \times 20 \times 40 \mathrm{~mm}^{3}$ specimens and then kept under water until testing or drying.

Compressive strength tests were then performed under the test regimes shown in Table 2.

\section{TEST RESULTS AND DISCUSSION}

The results shown in Figure 6 below show that the compressive strength is reduced by almost $40 \%$ where much moisture is present at high temperatures compared with corresponding dry conditions. Further, this high reduction in strength was shown to be independent of the boiling times (3,10 or 20 minutes) which seems to indicate that pore pressure is not the main effect in this high reduction of strength. The wet test specimens had a moisture content of $8 \%$ and in figure 6 the slope for $1.4 \%$ change in strength per $\%$ moisture is shown as this represents the room temperature effect from moisture in these tests. The results also show that there was no difference in strength for dried specimens tested directly from the drying oven or after cooling down to room temperature which confirms that the high reduction in strength after boiling comes from the presence of water. 
Table 2. Test program for compressive strength tests.

\begin{tabular}{|l|l|l|l|}
\hline Test regimes & $\begin{array}{l}\text { OPP [number of } \\
\text { tested specimens] }\end{array}$ & $\begin{array}{l}\text { 2PP [number of } \\
\text { tested specimens] }\end{array}$ & $\begin{array}{l}\text { 4PP [number of } \\
\text { tested specimens] }\end{array}$ \\
\hline $\begin{array}{l}\text { At room temperature } \\
\text { wet, directly from } \\
\text { storage under water }\end{array}$ & 6 & 6 & 6 \\
\hline $\begin{array}{l}\text { At room temperature } \\
\text { dry, dried to equilibrium } \\
\text { at } 105^{\circ} \mathrm{C} \text { then cooled } \\
\text { down to room temperature }\end{array}$ & 6 & 6 & 6 \\
\hline $\begin{array}{l}\text { Directly from } 100{ }^{\circ} \mathrm{C} \\
\text { boiled under water for } 3, \\
10 \text { or } 20 \text { minutes }\end{array}$ & $\begin{array}{l}3 \text { (boiled } 3 \text { min) } \\
\text { (boiled } 10 \text { min) }\end{array}$ & 6 (boiled 10 min) & 5 (boiled 10 min) \\
\hline $\begin{array}{l}\text { Directly from } 105^{\circ} \mathrm{C} \text { in } \\
\text { drying oven }\end{array}$ & 6 & 6 & 6 \\
\hline
\end{tabular}

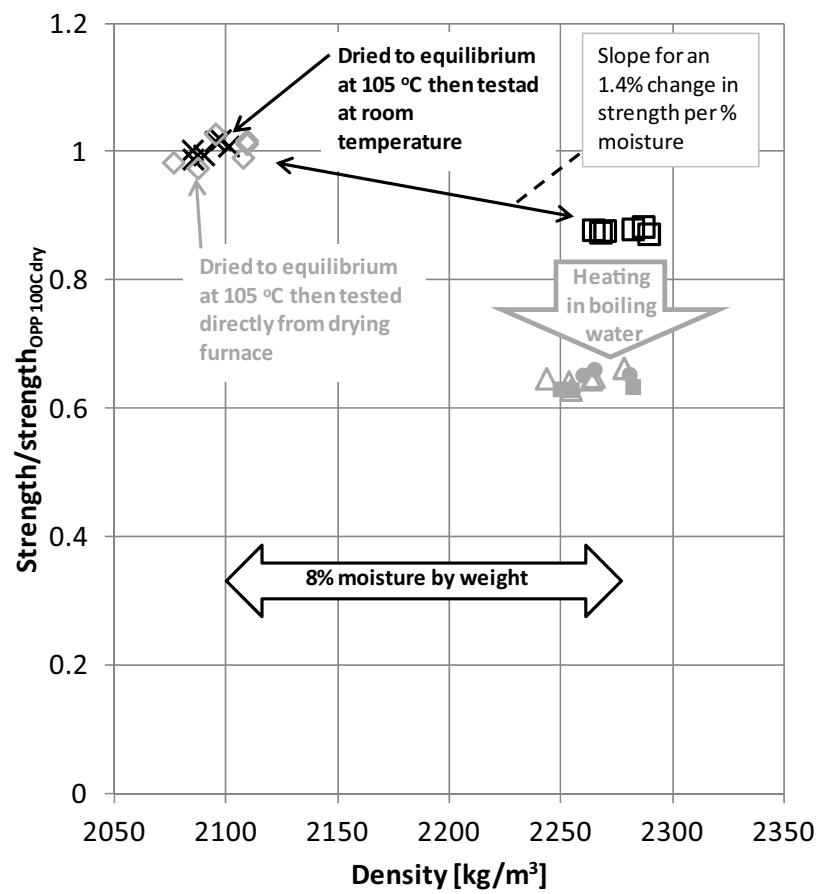

口OPP 20C wet

XOPP 20 dry

$\triangle$ OPP $100 C$ wet boiled 10 minutes

- OPP $100 \mathrm{C}$ wet boiled 3 minutes

OPP $100 \mathrm{C}$ wet boiled 20 minutes

$\diamond$ OPP $105 C$ dry

Figure 6. Differences in strength versus density for different pre conditioning, chosen reference is the average of the dry strength at room temperature. All specimens without an addition of PP fibres.

Boiling for 10 minutes gave a reduction of strength of $26 \%$ for the initially wet mortar specimens without an addition of PP fibres. This can be compared with the results for concrete reported by Lankard et al. [7] where the reduction was around $20 \%$.

All test results, including the tests on concrete with PP fibre additions, are shown in Figure 7. As indicated in the diagram the specimens containing PP fibres included more air and this change of air content gave a strength reduction of approximately $4.2 \%$ per percentage air which can be compared with $5.5 \%$ given by Neville for concrete mixes of water/cement ratios between $0.45-0.7$ [9]. Also notable is 


\section{MATEC Web of Conferences}

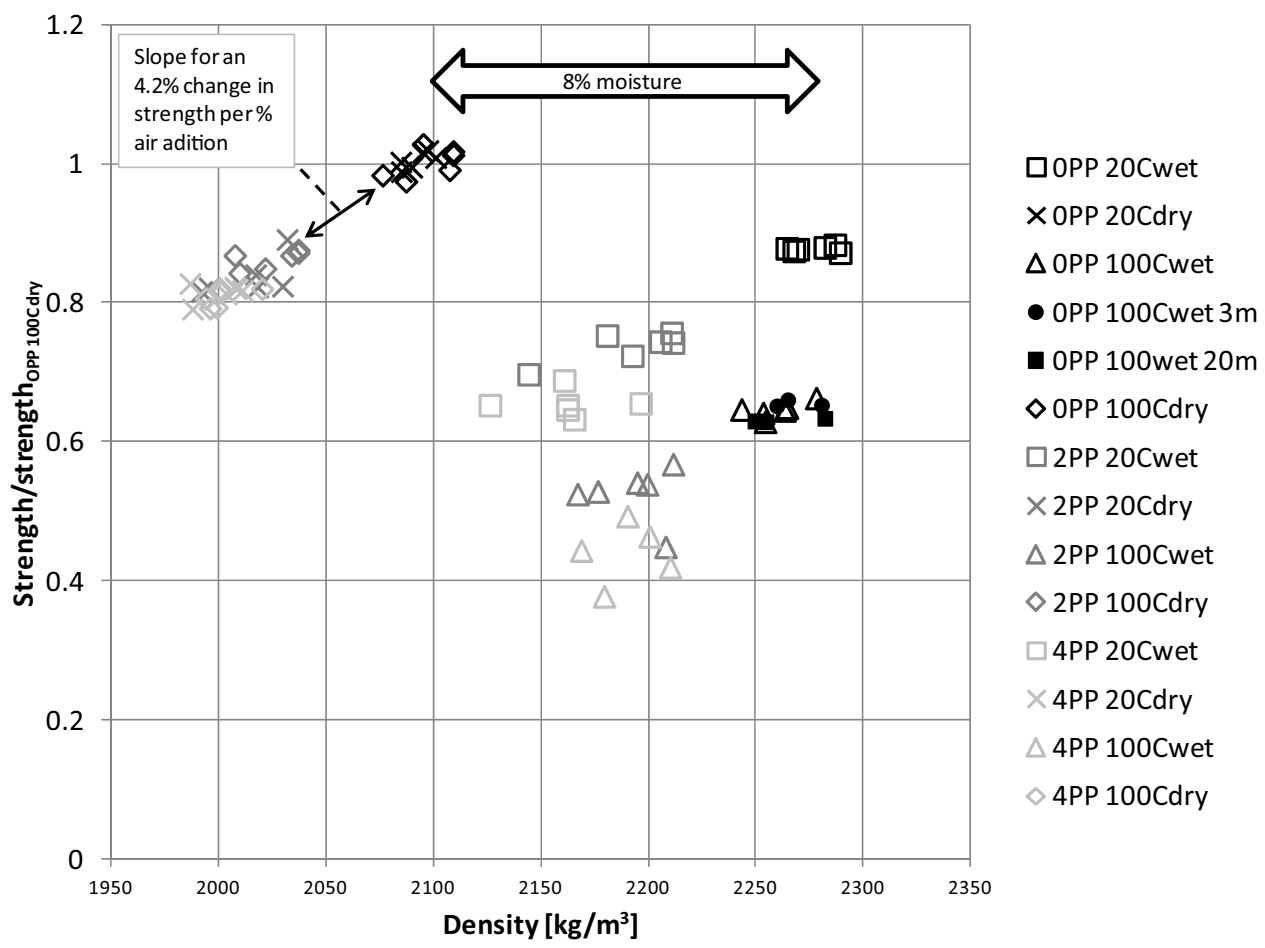

Figure 7. Differences in strength versus density for different pre conditioning, chosen reference is the average of the dry strength of the mix without a PP fibre addition at room temperature.

the higher spread in density between the different specimens containing PP fibres which indicates that the pores are not spread evenly in the matrix. The significance of this factor is increased by the size of the specimen as local effects have greater influence on small specimens.

\section{CONCLUSIONS}

Boiling for 10 minutes gave a reduction of strength of $26 \%$ for the wet mortar specimens without the addition of PP fibres compared to dried specimens. The results are not unique as it has been seen in many test series in the past that the strength is reduced when moisture is trapped inside heated concrete, i.e. if the test is performed when the temperature equilibrium is reached but not the moisture equilibrium. By testing small specimens and different boiling times the influence of pore pressure does not seem to be the main reason for this reduction in strength as no influence of the time of boiling was seen. As the moisture content at elevated temperatures are shown to influence the strength significantly in the literature as well as indicated by the experiments it partly confirms the theory presented in ref [10] where the moisture effects on mechanical properties in the critical zone (where the crack that leads to flaking appears) is suggested to be the cause of spalling, i.e. pore pressure is typically not the main cause of spalling during standard fire exposure. This is also indicated by the temperature measurements shown in Figure 3 where temperatures that correspond to very low vapour saturation pressure were measured at the time of spalling. Thus the function of PP fibres seems to be due to its ability to provide drainage pathways in the concrete in the critical zone. In the experiments presented here no mechanical effects could be seen due to the addition of PP fibres that could explain their influence on fire spalling. 
IWCS 2013

\section{References}

[1] Thelandersson S. 'Betongkonstruktioner vid höga temperaturer -en översikt' (in Swedish), VAST, September 1974.

[2] Harmathy TZ (1965) Effect of moisture on the fire endurance of building materials, moisture in materials in relation to fire tests. ASTM Special Tech Publ 385:74-95.

[3] Lange D., Sjöström J., Jansson R and Boström L., Deflection of concrete floor slab during a fire test: Testing and modelling, 15th International Conference on Experimental Mechanics ICEM15, Faculty of Engineering, University of Porto, Portugal, 22-27 July 2012.

[4] Jansson R., Boström L. (2010) "The influence of pressure in the pore system on fire spalling of concrete" Fire Technology, vol 46, no 1, pp 217-230.

[5] Jansson R., Boström L. (2009) "Fire spalling - the moisture effect" 1st International Workshop on Concrete Spalling due to Fire Exposure - From Real Life Experiences and Practical Applications to Lab-scale Investigations and Numerical Modelling, MFPA Institute Leipzig, Germany 3 - 5 September 2009.

[6] Bazant, Z.P., and Prat, P. C., Effect of temperature and humidity on fracture energy of concrete, ACI Materials Jour. 84 (July), 262-271.

[7] Lankard DR, Birkimer DL, Fondriest FF, Snyter MJ (1971) Effects of moisture content on the structural properties of portland cement concrete exposed to 500 F. ACI Special Publication SP 25, Detroit.

[8] EN 196-1:2005, Methods of testing cement-Part 1: Determination of strength, 2005.

[9] Neville A. M., Properties of concrete, Fourth Edition, 1996.

[10] Jansson R., Material properties related to fire spalling of concrete, Licentiate Thesis, Report TVBM-3143, Lund University, 2008. 